University of Northern Colorado

Scholarship \& Creative Works @ Digital UNC

President's Office

Administration

2001

Using a cognitive prosthesis to assist foodservice managerial decision-making

Andrew Hale Feinstein

James Edward Martin

Roy Ogawa

Follow this and additional works at: https://digscholarship.unco.edu/president 


\title{
Using a Cognitive Prosthesis to Assist Foodservice MaNAGerial Decision MAKING
}

\author{
ANDRew Hale Feinstein \\ William F. Harrah College of Hotel Administration \\ University of Nevada, Las Vegas \\ and \\ JAMES EDWARD MARTIN \\ Department of Psychology \\ The Pennsylvania State University \\ and \\ Roy OGAWA \\ Department of Computer Science \\ University of Nevada, Las Vegas
}

\begin{abstract}
The artificial intelligence community has been notably unsuccessful in producing intelligent agents that think for themselves. However, there is an obvious need for increased information processing power in real life situations. An example of this can be witnessed in the training of a foodservice manager, who is expected to solve a wide variety of complex problems on a daily basis. This article explores the possibility of creating an intelligence aid, rather than an intelligence agent, to assist novice foodservice managers in making decisions that are congruent with a subject matter expert's decision schema.
\end{abstract}

\section{INTRODUCTION}

Much has been made of replacing human intelligence with artificial intelligence (AI). Yet, with the exception of situations in which the context is relatively constant and the goals are well specified, the promises made by the artificial intelligence community have remained largely unfulfilled. This is now so widely recognized that even Bill Gates, the most recognized champion of the possibilities of computing power, noted in a recent book that although the dream of AI has been with us for a number of years, it has remained largely unrealized (Gates, 1996).

The reasons for the general failure of $\mathrm{AI}$ to date are controversial. Whether the difficulties are the result of certain matters of principle, or whether what is needed is more time and money, is a matter of continuing debate. We have our own views on the matter, and some of those have been published elsewhere (Kleindorfer \& Martin, 1983; Martin \& Kleindorfer, 1986; Martin, Kleindorfer, \& Brashers; 1987). It is not, 
however, the purpose of this paper to enter into that debate. Instead, we intend to take an end run around the problem, by not assuming that the dichotomous alternatives are either AI or human intelligence.

The AI community has proposed to produce either intelligent agents to assist human thinkers or computers that think for themselves (Allis, 2000; Bookman, 2000; Joy, 2000; Reed \& Tour, 2000). To date, these proposals have been notably unsuccessful in many of the everyday environments where problems that motivate the interest in computational techniques arise (Wilkes, 1992). However, these problems still create a need for increased information processing power in real life situations. In this context, it hardly seems acceptable to ignore the immense computational power available with modern technology.

Accordingly, the authors suggest a third approach - construct intelligence aids, not intelligent agents. That is, do not replace human intelligence with artificial intelligence, but merely provide it with assistance. This assistance would create a personmachine relationship whereby humans could enhance their decision-making abilities. This is well within the capacity of current computational technology. In fact, it is essentially what people have been doing at the practical level since the beginning of the computer revolution. Computers are not, and for the foreseeable future will not be, intelligent agents. Instead, they have, from the beginning, been aids to human intelligence. What is unique about this proposal is the form of the person-machine system envisaged.

\section{Cognitive Prostheses}

Sometime in the future it will be possible to extend the power of human intelligence and consciousness by augmenting it with computer power in ways analogous to how other prosthetic devices already extend human perceptual consciousness. For example, consider the role of a cane in extending the perceptual consciousness of someone who is blind. It is interesting to observe that, when a person is initially learning to use such a device, he or she remains primarily conscious of the cane. Experience of the street or the curb is not direct, and a conscious inferential process typically mediates it. Yet, after a good deal of practice, there is a significant shift in the form of experience. In this later stage, the curb is experienced directly, in a perceptual way, and not mediated by conscious inference. At the same time, consciousness of the cane moves into the background. In Heideggerian terms, the cane is transformed from "present-at-hand" to "ready-to-hand" (Winograd \& Flores, 1995).

We propose that, under the proper conditions, it will be possible to utilize computational systems in the same way the cane is used. In a properly organized personmachine system, it will be possible for a skilled human operator to "see through" the computational support similar to the way a skilled cane user can "see through" a cane. The key to an intelligence aid is that it be integrated into the users' cognitive processes so that it may become "ready-to-hand."

The person-machine system proposed here will depend essentially on two parameters: first, the formal input-output characteristics of the computational prostheses, and second, the skills required to utilize computational prostheses in a way that results in the extension of consciousness as described above. The prostheses we have in mind 
will, in accordance with the limitations of current computational systems, be modular components of the overall cognitive-perceptual system. The degree of flexibility they will be allowed to exhibit; with respect to either responding to contexts or in selecting goals, is an empirical question and will depend on the capacity of the user. In general, however, it is crucial that the input-output relation defined by the prostheses be well defined. This is necessary for good prosthetic devices. A flexible cane is not as good as a rigid one in providing guidance for the blind.

Moreover, the user must be trained to manipulate the cognitive prostheses in a way that touches the global, holistic characteristics of the world in which the user operates. This emphasis on user training is crucial. The possibilities inherent in the computational prosthetic system that is envisaged can only be realized to the extent that training and experience enable the user to "see through" the prosthesis to the world that is the object of thought and action.

Specifically, as a result of experience and practice, the user must become able to interpret changes in feedback from the computational system connected with the observed world as indicating informative alterations in the state of that world or the user's relation to it. Accordingly, the design of an effective prosthetic system must begin with an analysis of the general characteristics (knowledge, skills and cognitive capacities) of the user, as well as the relevant features of the cognitive prostheses.

Although two fundamentally distinct kinds of cognitive prostheses (CP) - a novice cognitive prosthesis (NCP) and an expert cognitive prosthesis (ECP) - will be developed, this theoretical work only discusses the development of the NCP. The primary differences between these categories of devices are based on the CP user's subject matter expertise. The ECP would be aimed at enabling a trained expert to utilize a full range of computational procedures as aids in performing a complex task. The NCP will focus on facilitating the training of novices so that they will be able to utilize the $\mathrm{CP}$ to perform a task-leaving undetermined whether the performance of that task requires an $\mathrm{ECP}$.

\section{A ConCrete EXAmple}

The NCP will be well suited to assist novice managers in making decisions that are congruent with a subject matter expert's decision schema in a particular domain. In the example below, the NCP is being used effectively in helping a novice foodservice manager emulate the judgmental abilities of a veteran manager.

On June 6, 2002, John Murphy's first day at Angelino's Trattoria was going to be an exciting experience - or so he thought. He had just graduated in May with a degree in Hotel and Restaurant Management and had been recruited to work at the 400 -seat local unit across the street from the restaurant chain's national headquarters.

Angelino's was a family owned multiunit foodservice operation with 23 outlets located in California, Nevada, and Arizona. The company's technologically savvy founder, Michael Angelino, was implementing a new NCP as the primary training device for all new assistant managers. John was going to be the first trainee to utilize the new system.

As John approached the host stand and asked for Mr. Angelino, he noticed that the 
server behind the podium was wearing a small microphone, an earpiece set and glasses. The upper-left corner of the left lens of the glasses was illuminated by a transparent blue-gray glow. Quickly, the host seemed to make comments to himself and then stated that Mr. Angelino would be there momentarily. A few moments later, Mr. Angelino appeared - wearing the same apparatus - and escorted John to the manager's office.

In the office - with walls covered by several stands of rack-mounted computers and equipment - John was provided with the NCP interface. It consisted of a wearable portable computing device that was attached around the hip, a head mounted wireless microphone and earpiece set, and horn-rimmed glasses. John thought the computer looked like a square fanny pack. He also noticed that it had a small handheld keypad attached to one of the computer ports. He strapped the small computer around his waist, and then put on the glasses and headset.

After some simple instructions by Mr. Angelino regarding proper hand placement on the input pads of the computing device, John noticed a transparent welcome screen appear in the glass of the left lens. In the center of screen, the words Welcome John to your first day of training! Click here to begin were scripted. He also noticed that the top of the screen had a horizontal bar with four equally spaced words: Help, Decision, Communicate, and Train. The lower part of the screen had three boxes: Locator - which currently had the word Office in it and a CADD drawing of what looked like the restaurant (John noticed navigational tools in this box, as well as small colored symbols in the drawing that seemed to be moving); Index - which had the words Training: Introduction highlighted within a scrolling hierarchical outline; and Mode - which currently stated Novice.

Mr. Angelino explained to John that the NCP would assist him in becoming a manager. He was to follow the screen's instructions and, if he had any questions, he could contact him though the Communication box. John heard these comments in both his uncovered left ear and through the small speaker that was over his right. He also noticed that the word Communicate was now flashing at the top of the screen.

John began his training session by using the touch-pad to select the main screen. The instruction began with a brief orientation of the computing interface. This was followed by a walk-through of the restaurant's facilities. The system guided John to the front of the house as well as the kitchens, storage areas, and loading docks. John noticed that the Locator box provided visuals on where he, each manager, the owner, and the employees were located. As he went through the training program, he also noticed that the Index box automatically scrolled from topic to topic.

Through the NCP, John learned how each station in the restaurant worked by monitoring several employees doing their jobs. In the front of the house, the NCP assigned him to monitor the host stand for two hours. The system explained and provided examples of appropriate server staffing configurations, customer reservation procedures, and table selection methods. In the kitchen, John witnessed several food items being prepared. The screen showed the ingredient list, procedures for preparation, cook times, pictures of food plating, and food costs per item. 
After completion of his three-day training period and subsequent hands-on examination, John was ready to take the floor and assist Susan- one of two floor managers. Susan assigned John to manage the host and bar areas for 3 weeks.

Answering the phone at the host station, John glanced at the welcome statement displayed in his glasses. Although he had almost memorized it, he still felt comfortable visualizing the last few words of the sentence - "How may I assist you?" He then listened to a customer request a reservation for four for tomorrow evening at 7:00 p.m. John immediately utilized the NCP's decision menu to ensure availability. He then entered the reservation into the system while the customer was still on the phone. The screen then prompted John to ask if there was anything else he could help with.

After hanging up the phone, a server approached and told him she was having a problem in the bar. She stated that a table of customers wanted to order dinner entrées in the bar. She told John that it was policy not to allow entrée orders in the bar when there was a wait for tables in the main dining room. John quickly used the help menu to look up policies on entrée service in the bar. He read that this policy was set by Mr. Angelino to deter customers from eating dinner in the bar rather than in the dining room, which had occurred on several occasions. This resulted in customers being unable to find a seat and order a drink while they waited for a table in the dining room.

The main screen provided several buttons that could be selected for additional information. One option was Customer Inquiry. Using this, John approached the table and explained the company's policy. While John was talking, the screen suggested what to tell the customer. John then stated that he would be happy to provide complimentary antipasti to the table. He also stated that the current wait for a table in the dining room was approximately 30 minutes. The customers thanked John and placed their names on the waiting list.

As John was walking back to the host station, the Communicate button briefly flashed and John heard Susan, say "John, I've got a call on line one regarding a large party of customers who would like to have dinner here next Saturday night. I would like you to handle the call." John immediately picked up line one at the host station and repeated the on-screen welcome statement. The caller-Bill Fredrick-stated that he was the operator of Excalibur tours and that he would like to send two busloads of tourists to the restaurant next Saturday night around 7:30 p.m. for dinner. The group would be attending a local sporting event that should end by 7:00 p.m. The head count as of today was 56 people.

John used the help system to query information on group reservations. The NCP suggested that John use the Simulation of Large Group Availability module under the Decision menu to estimate the mean customer count and party breakdown of the group to ensure availability. In the main simulation window, he was prompted with several entry fields to input information: Name, Date and Time of Reservation, Date and Time of Arrival, Current Head Count, Estimated Number of Patrons, Group Type, Maximum Occupancy of Transportation Vehicles, and Type of Event. John queried Bill for information about the group and entered as many fields of data as he could. 
After selecting the Continue button, the system paused and a readout screen appeared. Under the title of Historical Data, John read that Excalibur tours had dropped patrons off at the restaurant on eight occasions in the past year. The screen then showed the forecasted mean group size as 61 persons give or take 6 persons. The system discretely estimated the table sizes needed were 20 deuces give or take 4 and 6 four tops give or take 1 , and forecasted what percentage of customers would sit on the patio: $34 \%$ give or take $4 \%$. At the bottom of the screen it read Available, would you like to reserve? John selected yes. He ended the conversation by providing Bill with the on-screen reservation confirmation number and by thanking him for his business.

Sensing that this was John's first time reserving a large party, the NCP then switched to the Training mode and provided him with the necessary procedures for adjusting the indoor and patio table configurations, reviewing staffing, evaluating the need for-and methods of - contacting the two on-call servers. After John finished the training module, Susan came back on-line and requested that he meet her at the hot line.

Meeting John and Susan was Chris Lombard, the executive chef of Angelino's. Chris asked John if he could offer a chicken dish as a special for this evening. Chris explained that one of the local poultry distributors was running a special quantity discount on fresh, 8-ounce breast portions and that he had purchased 75 pounds.

John searched for menu specials and found the simulation module Menu Item Integration. John selected the main ingredient as Chicken Breast and pulled up 10 recipes from the database that Chris had created. The first recipe was for Chicken Parmigiana.

John ran the recipe simulation module for Chicken Parmigiana to determine the effect of running a chicken special for the next few evenings. The NCP responded that this particular dish required the use of the deep fryers, and that this menu item, coupled with other current specials, could overburden this piece of equipment and drop the fry oil temperature below the critical fry point. This problem could reduce the quality of the dish during peak hours. The NCP then suggested several chicken dishes that did not require the use of the deep fryer. As a result, John selected the Chicken Piccata.

For the next several weeks, John continued to use the NCP as a training device. John eventually became cognizant of the operational characteristics of the restaurant and the duties and responsibilities that Mr. Angelino required. Soon, the NCP became less of an instructional system and training device and more of a tool to solve problems and assist in decision making. In effect, it became an ECP.

\section{NCP PROTOTYPE}

An NCP Prototype as discussed above - consisting of a wearable computer with wireless Internet capability and a positioning system-is currently under development. Figure 1 provides a screen grab of the interface that we are continuing to build. 


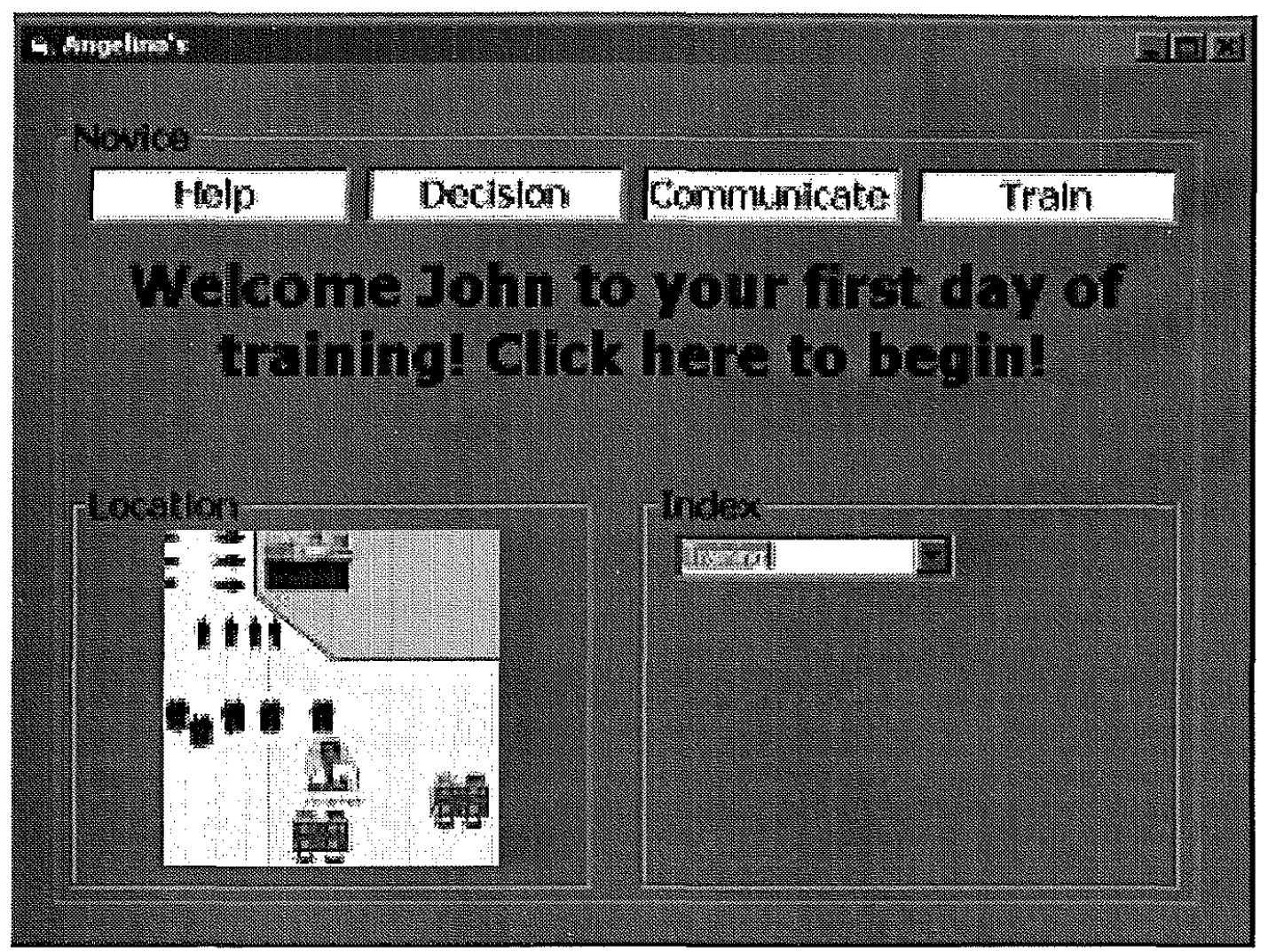

FIGURE 1

SCREEN GRAB OF NCP

Input is by a hand keyboard and hand-held pointing device as well as an audio earset microphone system. Output is by means of an optical display and an audio earset. One or more desktop base stations will also be available (we will consider them as one system and speak below of "the base station" in the singular).

The NCP has an architecture roughly described in Figure 2. The four boxes and two display symbols represent major screen areas as discussed in the example. The central area of the screen displays the user-selected application. In Figure 1, the display is providing the first screen of training. A module represented by a display symbol marked with "Location" controls the display of the restaurant interior and another represents the display of the user-interaction context. The four boxes represent major subsystems of NCP: Help, Communications, Decision Making, and the Tutorial.

Although undeveloped at this time, major subsystems supporting the Help subsystem context include a factual information database, a rule and procedure database, and an expert system knowledge base. A module for telephone-like connections and conversation using the transmission of voice over the Internet will be included in the communications module. The decision-making module will be supported by a spreadsheet-like interface for what-if calculations and a set of models of various processes 


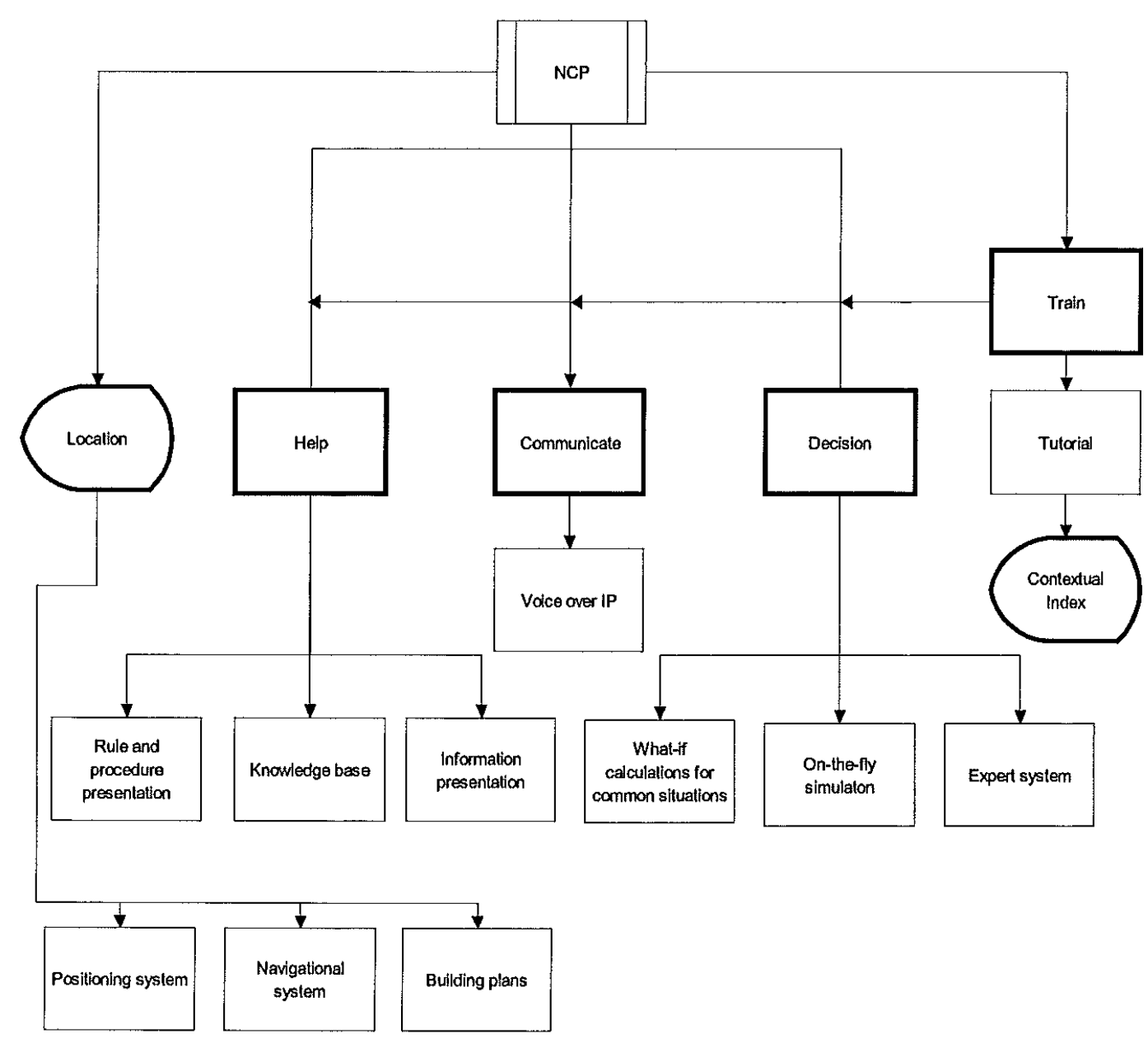

FIGURE 2

CONCEPTUAL MODEL OF NCP

of the restaurant. Each model simulating processes of the restaurant can be reparameterized and executed on the fly or, if more complex, executed by the base station. Feinstein and Mann (1999) provide an example of this simulation model.

The location module, which shows the location of restaurant personnel, must be supported by a positioning system, a navigation system, and a database of building plans (Motorola has recently developed these technologies.). These subsystems will be executed in the base station, which provides location sensing and sends the data to each NCP.

The contextual index displays the position of the novice manager in the context of the learning process. The training module is able to call upon and control the functions of the Help, Communications, and Decision modules during training. 


\section{Software}

The graphic user interface (GUI) for the CP will require minimal input from the user. This is being accomplished by developing a pull-down menu system using Visual Basic 6.0 (VB) (See http://msdn.microsoft.com/vbasic/). The object-oriented programming capabilities of VB will allow us to complete a program as described in the contextual example above.

Modules of the CP, such as Help, Decision, Communicate, and Train, will be developed in such a way that navigation and user input is limited to pointing and a few keystrokes. Allowing modules to run independently and be controlled by the user through a single GUI can do this.

Using the Arena simulation software package developed by Systems Modeling Corporation (http://www.sm.com), the authors are currently replicating the dynamics of a particular foodservice operation. Upon the user inputting a customer arrival distribution, the module provides quantitative data, such as average estimated equipment, needed table, and server utilization.

\section{NCP HARDWARE ARCHITECTURE}

A CP is essentially a wearable computer. These devices have been manufactured since the 1960s when Ed Thorp and Claude Shannon discussed their 1961 invention of the first wearable computer - a cigarette-pack sized analog computer used to predict the outcome of roulette (Thorp, 1966).

Wearable computers are always-on computers that are comfortably worn and used by the operator (Rhodes, 1997). In essence, they are a "device that is always with the user, and into which the user can always enter commands and execute a set of such entered commands, and in which the user can do so while walking around or doing other activities" (http://wearcomp.org/wearcompdef.html). Further, wearables have the "full functionality of a computer system [and are] inextricably intertwined with the wearer" (http://wearcomp.org/wearcompdef.html).

Wearable computer hardware is primarily comprised of five distinct components: computing system, display mechanism, portable power supply, input interface, and wearable enclosure. Each of these components is discussed in detail below.

\section{Computing System}

Wearable computing design and architecture have evolved rapidly over the years. MIT's wearable computing laboratories have been working on a design standard in this area for years (DeVaul, Rhodes, \& Schwartz, 2000). Termed "Lizzy," this design specifies using the $\mathrm{PC} / 104+$ computer architecture as the primary embedded system architecture for wearables (Starner, 1997).

The PC/104 architecture is comprised of stackable circuit boards measuring about 4" $\times$ 4" (Arrick Publishing, 2000). These boards can be configured to create an embedded system - a computer "embedded" in another device. Each circuit board is 
comprised of a module that can consist of a CPU, video controller, network interface, sound $\mathrm{I} / \mathrm{O}$, and data acquisition board. This architecture is currently implemented in a variety of products, such as machinery, automobiles, vending systems, and wearable computers. The $\mathrm{PC} / 104+$ architecture includes a peripheral component interface $(\mathrm{PCl})$ bus and is backward compatible to legacy architectures.

Other proprietary architectures for wearable computing systems have also been developed. Several of these manufacturers are listed in Table 1.

TABLE 1

WeARABle Computing System Developers

- Intel's StrongARM Microprocessor

http://developer.intel.com/design/strong/

- Motorola's ColdFire Processor

http://www.motorola.com/SPS/HPESD/

- ZFLinux's Machz and SystemCard - they also produce a PC/104 system http://www.zflinux.com/

- $\quad$ Hitachi's SH-3

http://www.hitachi.com/

- $\quad$ TIQIT's MPC

http://www.tiqit.com/

- IBM's and Olympus' unnamed wearable computing system http://news6.thdo.bbc.co.uk/hi/english/sci/tech/newsid\%5F538000/538072.stm

- $\quad$ Adaptive Systems' nC52

http://www.adaptivesystems.com/

- Xybernaut's Mobile Assistant IV

http://www.xybernaut.com/

Although the NCP hardware has not been selected, Xybernaut's MA IV is one of the most widely used wearable computing systems and seems to be the logical choice. In December 1999, Popular Mechanics bestowed the 2000 Design \& Engineering Award on the MA IV for innovation and design (Oldham, 1999). The MA IV computing system, running a Pentium $233 \mathrm{MHz}$ with $64 \mathrm{MB}$ RAM and $2.1 \mathrm{~GB}$ hard drive, sells for approximately $\$ 4,000$, and a complete system averages $\$ 6,500$. 


\section{Display Mechanism}

Several different types of displays have been developed to use with wearables. Head-mounted and hand-held/wrist-worn (typically flat panel touch-screen displays) are the most common. The CP utilizes a head-mounted display to increase the transparency of the system for the user. Although hand-held/wrist-worn displays are being used effectively in hospitals and maintenance facilities, they seem to distract the user when dealing with interpersonal situations (for a discussion of future display technologies, see http://lcs.www.media.mit.edu/projects/wearables/HUD-paper/HUD. html).

Head-mounted displays typically use microdisplay technology. Manufacturers have been able to create a $1 / 2$ - inch diagonal active-matrix SVGA display capable of $800 \times 600$ resolution. When used in conjunction with concave reflectors that transmit images to the eye, the viewer perceives a 17-inch monitor, located 2 feet away. The primary method of mounting a microdisplay is on a boom, a pair of glasses, or a hat. Several microdisplay manufacturers are available on-line and are listed in Table 2.

TABLE 2

Microdisplay Manufacturers

- The MicroOptical Corporation

http://www.microopticalcorp.com/

- Colorado MicroDisplay, Inc.

http://www.comicro.com/index.html/

- Tek Gear

http://www.tekgear.ca/

- Displaytech, Inc.

http://www.displaytech.com/

- $\quad$ Planar System, Inc.

http://www.planar.com/

\section{Portable Power Supply}

A variety of batteries can be used to power the wearable - provided that the correct converter, switching regulator, transistors and power management software are installed (Post, 1996). However, companies such as Xybernaut and NRG Research Inc. (see http://www.nrgresearch.com/) sell battery configurations specifically designed for portability and seem to be the logical choice. 


\section{Input Interface}

Several input interfaces are available for wearables. Peripherals commonly utilized today include hand-keyed input devices, flat-panel displays, and voice recognition configurations. Several of these interfaces are discussed below.

Hand-keyed Input. Handkey Corporation's Twiddler is a pocket-sized device that functions as a keyboard and a mouse. The keyboard uses the "Chord" keying method (pushing one or more keys simultaneously) for input, and the mouse is based on gyroscoping technology (see http://www.handykey.com for further information). This product sells for approximately $\$ 200$.

Wrist-worn keyboards are small QWERTY keyboards that attach to the user's forearm for accessibility. L3 Systems' WristPC Model FA4 (see http://www.13sys. com/) and Xybernaut's XyberKey are good examples of this device.

Flat Panel Displays. There are also several flat panel display manufacturers that sell touch-screen LCDs for use with portables. These displays are typically 6" to 8" diagonal active matrix and are worn on the wrist or stored in a pouch. Input is through touch or the use of a stylus.

Voice Recognition. Although not perfected, voice recognition software/hardware combinations are rapidly becoming useable input devices for wearables. Most wearables have I/O ports for sound and are full duplex SoundBlaster compatible. Recent improvements in speech recognition software have "boosted accuracy levels to as high as 98 percent" (Alwang, 1999). In the near future, this technology will eliminate the need for a hand-keyed input device for the CP. Although the CP might utilize voice recognition for input, it will not be the sole method of navigating the system. Two of the most widely used voice-recognition software packages are Dragon Systems Dragon NaturallySpeaking and IBM's ViaVoice (Alwang, 1999).

\section{Future Interface Products}

Vaughan Pratt, a leading researcher on wearable computers at Stanford University, is working on a computer-based sign language dubbed ThumbCode (Kleiner, 1999). This interface allows a user to wear an electrode-embedded glove to touch his or her thumb against different finger digits. As the user touches different digits, software converts these inputs into alphanumeric characters or commands.

Retinal navigation is another area of evolving research. These devices allow headmounted displays to also act as input interfaces. Sophisticated tracking hardware and software identify where the user is looking and utilize this information to signal input selection. This technology is currently available on some cameras, communication devices for the physically challenged, and medical applications. The University of Washington's Human Interface Technology (HIT) focuses on this type of technology (see http://www.hitl.washington.edu/). 


\section{Wearable Enclosure}

Wearable enclosures allow the user to attach wearables to their bodies, and several types and configurations are available. Belts and vests are the most common at present.

A simple belt or fanny-pack configuration can be used to attach the wearable to the body. More sophisticated enclosures include specialized vests and wearable clothing.

German medical personnel currently use the Noah Vest as part of a portable communication device. The bright-red vest houses a modified Xybernaut MA IV wearable that allows physicians in the field to communicate with emergency room physicians. Noah is an acronym for "Notfall Organisations- und Arbeits- Hilfe." This translates roughly into "Emergency Organization and Work-Aid" (Nerlich, 2000).

Mann (1996, 1997, 1998), who has written several articles on wearable clothing, believes that wearables and peripherals can be woven into the fabric of a user's clothing and shoes. He hypothesizes that eventually one will not be able to tell who is wearing a computer.

\section{CONCLUSION}

In this article, The authors' goal has not been to create computers that solve complex problems on their own, but to provide a system to assist managers. The CP envisioned will not be an intelligent agent making decisions without human intervention. Rather, it will be an intelligence aid assisting managers - both novice and expertwith their judgmental ability.

Developing and implementing a CP is not a futuristic theory. It is an attainable goal that can be accomplished utilizing today's technologies. In fact, the U.S. Army has already developed similar products that provide pertinent information to soldiers and commanders in the field.

It is not our intent to create foodservice manager automatons, but rather to enhance human managers' abilities to reason, a skill that has been elusive in AI devices. The authors are currently developing a working prototype of an NCP to be implemented and tested in a foodservice operation in the next 18 months. Empirical results of these tests will be reported in subsequent publications.

\section{REFERENCES}

Allis, S. (2000, April 16). I, robot. Boston Globe, p. D1.

Alwang, G. (1999). Speech recognition. PC Magazine [On-line]. Available: http:// www.zdnet.com/products/stories/reviews/0,4161,2388289,00.html

Arrick Publishing. (2000). PC/104 embedded systems FAQ. The On-Line Journal of PC/104 Embedded Systems [On-line]. Available: http://www.controlled.com/ pc104faq/ 
Bookman J. (2000, April 2). Building a computer from brain cells series: The human, wired: PART III. The Atlanta Journal-Constitution, p. A14.

DeVaul, R. W., Rhodes, B., \& Schwartz, S. (2000). The MIT Wearable Computing Web Page [On-line]. Available: http://lcs.www.media.mit.edu/projects/wearables/

Feinstein, A., \& Mann S. (1999). The development and assessment of a foodservice instructional simulation technique (FIST). Journal of Hospitality and Tourism Education, 10(3), 19-27.

Gates, B. (1996). The road ahead. New York: Penguin Books.

Joy, B. (2000, April). Why the future doesn't need us. Wired, 8(04), 238-262.

Kleindorfer, G. B., \& Martin, J. E. (1983). The iron cage, single vision, and Newton's sleep. Journal of Philosophy and Technology, 3 .

Kleiner, K. (1999). Rule of thumb. The New Scientist [On-line]. Available http:// www.newscientist.com/ns/19990227/newsstory9.html.

Mann, S. (1996). "Smart" clothing. The Personal Imaging WWW Site [On-line]. Available: http://www.wearcam.org/smart_clothing/

Mann, S. (1997). Smart clothing: The "wearable computer" and WearCam. Personal Technologies, $1(1)$.

Mann, S. (1998). Definition of "wearable computer." The International Wearable Computing WWW Site [On-line]. Available: http://wearcomp.org/wearcompdef.html

Martin, J. E., \& Kleindorfer, G. B. (1987). Mind as a rule-governed device. Logos, $\underline{7,35-56 .}$

Martin, J. E., Kleindorfer, G. B. \& Brashers, W. R. (1987). The theory of bounded rationality and the problem of legitimation. Journal for the Theory of Social Behavior, $63-82$.

Nerlich, M. (2000). The Noah vest. Xybernaut Germany Application Briefs [Online]. Available: http://www.xybernaut.de/download/uniregensburg_noahweste_e.pdf

Oldham, J. (1999). Popular Mechanics Design \& Engineering Awards 2000. Xybernaut in the News [On-Line]. Available: http://www.xybernaut.com/product/ clippings/pop_mech.htm

Post, R. (1996). The HackMan 0.4 wearable computer. Rehmi's Work Page[Online]. Available: http://physics.www.media.mit.edu/ rehmi/hackman.html

Reed, M. A., \& Tour, J. M. (2000, June). Computing with molecules. Scientific American, 282, 86-93. 
Rhodes, B. J. (1997). The wearable remembrance agent: A system for augmented memory. Personal Technologies, 1(1), 218-224.

Starner, T. (1997). Lizzy wearable computer assembly instructions. Wearable Computing Project [On-line]. Available: http://lcs.www.media.mit.edu/projects/ wearables/lizzy/index.html

Thorp, E. O. (1966). Beat the dealer (new ed.). New York: Vintage.

Wilkes, M. V. (1992). Artificial intelligence as the year 2000 approaches. Communications of the ACM, 35(8), 17-20.

Winograd, T., \& Flores, F. (1995) Understanding computers and cognition: A new foundation for design. New York: Addison-Wesley. 